\title{
Economic recession and health
}

\author{
Eleni Theocharous \\ Member of the European Parliament, Cyprus, Paediatric Surgeon
}

\begin{abstract}
The economic crisis, which struck in Europe since 2008, has raised concerns about the health of the less privileged, vulnerable and poor people of the continent - the ordinary people of Europe. There is currently sufficient evidence for the negative and, in certain countries, devastating effects of austerity policies on the financing of health and other services of general interest, essential to promote the proper functioning of our economies and the cohesion of our societies. This evidence proves that health and social services are seriously impaired.
\end{abstract}

\section{Economic recession and health}

The financial strain on Member States in general, and on health and social services in particular, "triggered" policy measures that are likely to have a negative effect on the health and the wellbeing of patients, as well as the employment conditions of health workers.

However, despite more than 100 years of research about the effects of economic turbulence on health, the relation between the two is yet not fully clarified.

The newly elected European Commissioner on Health and Food Safety, Vytenis Andriukaitis, reported that "health is a part of every policy in the Commission Strategic Agenda" and that "citizens' health and safety is the cornerstone of our social market economy".

We all know very well, that this is what the Treaty requires in all the policies and actions of the European Union. In fact, this is the reality: in the EU we have some of the highest standards in the world, in terms of health and food safety.

Despite this, another annoying reality is the fact that we have not advanced the task of studying the correlation between the financial crises - past, present or even future ones - austerity measures and health recession.

Correspondence: Eleni Theocharous, Member of the European Parliament, Cyprus, Paediatric Surgeon

E-mail: elenitheocharous@cytanet.com.cy

Key words: devastating economic crisis; health; Europe effects.

(C) Copyright E. Theocharous, 2014

Licensee PAGEPress, Italy

Thalassemia Reports 2014; 4:4867

doi:10.4081/thal.2014.4867

This article is distributed under the terms of the Creative Commons Attribution Noncommercial License (by-nc 3.0) which permits any noncommercial use, distribution, and reproduction in any medium, provided the original author(s) and source are credited.
For example, past crises such as the Bovine Spongiform Encephalopathy (BSE) and the Severe Acute Respiratory Syndrome (SARS), which caused major economic losses, have further shown the economic value of strong health protection, which I intend to pursue. I strongly believe that the global economic downturn is likely to have ripple effects on health and social spending, especially in developing countries whereas the public health effects of the economic crisis are already visible, particularly in countries most affected by recession Only Iceland has so far avoided negative health effects.

Strong social protection mechanisms (both formal and informal) can mitigate some negative effects of recession on health. A great example of an informal mechanism for social protection in Cyprus and Greece is that volunteer Organizations have established Medical centers spread around the country, offering health services, free of charge to all those in need, whereas many volunteers are working intensively, raising funds and supporting directly chronic patients with palliative, psychological or supporting care, mainly at home.

Austerity measures can exacerbate the short-term public health effect of economic crises. These cost-cutting or increased cost-sharing in health care policies, not only reduce access to health services but they also shift the financial burden to households.

Policy responses to a similar set of economic shocks varied between countries and have led to differing health outcomes, creating potentials for future research. This is important in order to understand how economic reforms may possibly affect health, and mitigate risks, and why some societies are more resilient than others.

Economic crises and their counter-measures have pronounced and unintended effects on public health, yet, public health experts have remained largely silent during this crisis.

Promoting investments in health and social structures is essential to maintain stability and security, and accelerate economic recovery. The challenge facing the world now is to prevent an economic crisis becoming a social and health crisis.

We need a new strategy for Health in Europe, if we are to improve Health Services, create jobs and boost Growth. Better Health Services and better Health of the individual encourage growth.

Therefore, as an MEP and as a Medical Doctor but also as a Human Rights Activist, I intent to actively engage in promoting investment in health, as one of the most effective investments in the European Human Capital and as an investment in our future.

The recent economic and financial crisis has great social consequences especially concerning unemployment. More precisely, the unemployment rate has increased continuously from $7.2 \%$ in 2007 to $9.7 \%$ in 2010 and $11 \%$ in 2013 in the EU- 28, and by similar rates in the euro zone. Of even greater concern, is the deterioration in youth unemployment rates.

Another impact of the financial crisis concerns public health and the increase in suicide rates since the psychological status of unemployed young people is severely impaired. According to a study published in the British Journal of Psychiatry, the recession has been responsible for 100,000 suicides across Europe and North America; primary factors being unemployment, home repossession and insurmountable debt.

Also self-report unmet need for medical examination or treatment. 
The Europe-wide average for self-reported unmet need in the first Quintile of equalized income (lowest income), has remained relatively stable over the crisis period, but statistics within some Member States are a cause for concern

It is, however, still early to comprehensively evaluate the impact of the economic crisis upon the population's health. Concrete data and comparisons remain scarce. Nonetheless, some general trends and indications can be found.

A WHO study reveals that in countries implementing austerity measures, re-emergence of malaria and transmission of dengue fever have occurred, whilst in Greece, a major upsurge in HIV infections amongst intravenous drug users, has been reported.

Additional Eurostat data and other research show a 32\% increase in the number of stillbirths and a reversal of the long-term decline in infant mortality in Greece.

It seems that the long term impact of reduced access to health care is widely acknowledged, even though precise implications will not be known for several years.

Health equity is also a major concern, with a new stream of research being launched recently whereas on the other hand people in Europe are consuming less healthy foods. "Real food" spending has fallen dramatically from 2007 to 2012 , and instead, we are purchasing cheaper, unhealthier, processed and fatty foods.

The economic crisis has affected Europe's health systems in a variety of ways. With an impact upon budgets, healthcare professionals and hospitals, as well as some of the measures taken by Member States in response to the crisis and their health implications.

First of all, we have the decrease in health budgets. On average, health, accounts for around $13 \%$ of government spending in the European region. The proportion of public spending dedicated to health has fallen in most Member States since 2008.

In response to the need to curtail health budgets and in pursuit of more sustainable financing, many Member States have taken measures in relation to staffing, resources and service provision which affect the quality of services, especially those of the public sector, the functioning of the health system and the access to health care for European patients.

Governments in Austria, Latvia, Poland and Slovenia used the economic crisis as an opportunity to strengthen their positions in price negotiations with pharmaceutical companies whereas governments in Denmark, Greece, Latvia, Portugal and Slovenia have accelerated hospital reforms. In Cyprus, Greece, Ireland, Lithuania, Portugal and Romania, salaries of health professionals have been reduced. Meanwhile in Denmark, the UK and Slovenia, a freeze on salaries has been applied while in several countries, plans to improve the health sector were abandoned in order to keep control of costs.

Three more negative consequences of the health budgets cuts are hospital closures, cuts to services and the impact upon health care professionals.

Some of the measures taken to reduce costs have directly reduced the availability of frontline services and institutions. This means that basic human rights of individuals are being violated. Especially the rights to health and life. Access to health services is reduced for the most vulnerable, migrants, unemployed youngsters, elderly people, patients suffering from chronic diseases and the poor.

For example, according to a WHO report, in 2010 , only $23 \%$ of those in need for anti-retroviral treatments in Eastern Europe were receiving it, while the global coverage is $47 \%$ for low and middle income countries.

Un-documented migrants and people over 26 years old, who have not been able to enter the labor market, will be excluded from receiving public care. Concerning healthcare professionals, it is well-known that in addition to cutting health budgets and resources, Member States have adopted measures which directly affect those responsible for delivering health care. In particular, nurses' salaries have been reduced in many countries, exacerbating the problems caused by labor migration and putting strain on hospitals and surgeries.

It's obvious that brain drain, unemployment of new scientists and lack of personnel, combined with lack of quality, lead to a dramatic fall of the level of health services.

Governments reacted to these consequences of the crisis by implementing certain measures in order to improve access to services. A number of them have begun to take steps to mitigate the effects of the crisis changes, which have reduced access to services. The aim of this effort is to minimize the psychological negative impact of the crisis over the population, the diminishing of waiting list and for easiest access to primary health centers.

The transparency of waiting list targets and guarantees has been introduced, extended or enhanced in the Czech Republic, Hungary, Estonia, Slovakia, Slovenia, Spain and the UK. Meanwhile greater use of private sector capacity to reduce waiting times has been made in France and Malta and existing user charges for primary care have been removed in Croatia, on the basis of evidence that they discourage use of such services.

The conclusions of the last EMPLOYMENT, SOCIAL POLICY, HEALTH and CONSUMER AFFAIRS Council meeting in Luxembourg, on the 20th of June 2014, are of great importance since they called Member States to:

1. Continue improving further access for all, to high quality healthcare services, paying particular attention to the most vulnerable groups;

2. Strengthen further health promotion and disease prevention policies and strategies aiming at improving people's health, thereby reducing the need for curative care;

3. Consider innovative ways of integration between primary and hospital care, and between health and social care;

4. Promote the implementation of Information and Communication Technologies and Innovations, especially for chronic diseases and of course e-Health solutions to ensure quality of care and Health literacy, and improve efficiency and effectiveness of health systems and also control of expenditures;

5. Better use of the Health Systems Performance Assessment (HSPA) for policy-making, and improving transparency and accountability at national level;

6. Further Cooperation on sharing information on strategies to effectively manage pharmaceutical and medical devices expenditure, while ensuring equitable access to effective medicines within sustainable national healthcare systems and, using existing groups where relevant.

7. Continue discussions on issues related to affordable pricing, use of generic medicines, orphan medicines, medical devices and small markets.

8. Draw lessons from the crisis and promote universal access to high quality healthcare while taking into account its different components, so that necessary health reforms can be accomplished without compromising the functioning of health systems as part of social safety net;

9. Exchange information on the healthcare services covered by the Member States' healthcare systems, inter alia within the context of the Working Party on Public Health at Senior Level;

The Council also invited the Member States and the Commission to:

1. Support effective implementation of the EU objective to ensure a high level of human health protection in the definition and implementation of all Union activities and policies;

2. Continue the dialogue aimed at improving the effective use of European Structural and Investment Funds (ESIF) for health investments in eligible regions of Member States; and make further efforts to promote the use of the Union's Financial Instruments including the European Structural and Investment Funds (ESIF) for investing in health, in order to attain in particular the objectives of these conclusions. 
3. Evaluate existing information to assess the role that healthcare benefits play in reducing health inequalities and the risk of the population falling into poverty;

4. Aim at reaching a common understanding on the most effective resilience factors, including those proposed by the Commission in its recent communication, on effective, accessible and resilient health systems, and request the Working Party on Public Health at Senior Level to illustrate best practices on how to implement them in different health systems;

5. Strengthen cooperation in the following fields, agreed in the Directive on the application of patients' rights in cross-border healthcare: cross-border cooperation at regional level, European reference networks, e-Health, and Health Technology Assessment (HTA);

6. Building on the outcomes of the Action Plan for the EU health workforce and with particular attention to the recommendations from the Joint Action on health workforce planning and forecasting, to further cooperate on strengthening health workforce policies in the Member States in order to ensure sustainable health workforce with the necessary skills and on the guarantee accessibility, safety and quality of care;

7. Continue to strengthen the effectiveness of health systems through identifying tools and methodologies for Health Systems Performance Assessment (HSPA), the exchange of best practice and for better use of existing data services, such as Eurostat and OECD statistics;

8. Reinforce cooperation and better coordination between the Social Protection Committee (SPC) and the Working Party on Public Health at Senior Level (WPPHSL) so that Ministries of Health can actively contribute within the framework of the European Semester.

Last but not least, invited the Commission to:

1. Promote the exchange of information and best practice in the field of accessibility taking into account its different components. To support projects in order to promote and develop periodic collection of information and to produce scientific evidence on equitable access to care with a view to addressing the problems in achieving universal and equitable access;

2. Support, as appropriate, exchange of information between Member States on policies related to pharmaceutical products and medical devices, with particular attention being paid to small markets;

3. Encourage cooperation to improve the complementarity of health services for those living close to Member States' borders that may need to access healthcare across borders;

4. Provide information on the healthcare services covered by the Member States' healthcare systems, using the information provided by the National Contact Points established in accordance with the Directive on the application of patients' rights in cross-border healthcare.

EU priorities in three words include promotion, protection, and prevention. The key priority will be to both deliver real benefits to citizens and support key sectors of the EU economy, such as the healthcare sector - a major job creator - as well as the agro-food industry which can only prosper, if trade flows under safe conditions. Promoting Europe's economic recovery is a key objective, and health and food safety policies can make a significant contribution.

As regards to priorities on public health, against a background of population ageing, growing burden of chronic diseases and increasing demand for healthcare, efforts will be supported to make health systems more efficient and innovative; so that they can provide equitable healthcare to all citizens, while remaining financially sustainable. As much of the disease burden and related expenditure is preventable, the intention is to put more focus on enhancing prevention. The more health systems invest in prevention now, the less they will pay in treatment in the future.

In several European Union countries, the financial crisis coupled with structural health and social insurance reforms have had numerous repercussions affecting healthcare services, health professionals and patients across Europe. Patients already affected by the reduction in services and the out-of-pocket payments incurred, have seen a considerable decrease in the access and affordability of care.

We have the tendency to blame mainly the dysfunction of the health sector, the lack of means and the reduction of the wages of doctors and nurses. But at the end of the day, the professionals are the ones who suffer but patients are the ones who actually pay for it; mostly people belonging in vulnerable social groups, people suffering severe and chronic diseases like cancer, AIDS, cardiovascular disorders, Rheumatopathies, Haemoglobinopathies, rare Anaemias, psychological disorders and many others.

So, we have to focus on the patient's well-being and on finding the means and methods in order to respond to patient's problems in order to assure a high level of health care for all people. 